\title{
Correction to: Use of antipsychotics and long-term risk of parkinsonism
}

\author{
Angelo d'Errico ${ }^{1}$ Elena Strippoli ${ }^{1} \cdot$ Rosario Vasta $^{2} \cdot$ Gianluigi Ferrante $^{3,4} \cdot$ Stefania Spila Alegiani $^{3} \cdot$ Fulvio Ricceri $^{1,5}$ \\ Published online: 3 November 2021 \\ (c) Fondazione Società Italiana di Neurologia 2021
}

Correction to: Neurological Sciences (2021)

https://doi.org/10.1007/s10072-021-05650-z

Originally, the article has been published online with inverted author names. This has been correctly presented here.

The original article has been corrected.

Publisher's note Springer Nature remains neutral with regard to jurisdictional claims in published maps and institutional affiliations.

The original article can be found online at https://doi.org/10.1007/ s10072-021-05650-z.

Rosario Vasta

sarovasta@gmail.com

1 Epidemiology Unit, Piedmont Region, ASL TO3,

Grugliasco, Italy

2 ALS Center, 'Rita Levi Montalcini' Department of Neuroscience, University of Turin, Via Cherasco, 15, 10126 Turin, Italy

3 National Centre for Drug Research and Evaluation, National Institute of Health (ISS), Rome, Italy

4 Center for Oncology Prevention Piemonte, Città della Salute e della Scienza, Turin, Italy

5 Department of Clinical and Biological Sciences, University of Turin, Turin, Italy 